\title{
Examining the Geochemical Behavior of Sulfur in Highly Reduced Planetary Bodies: Insights from X-Ray Absorption Near Edge Structure (XANES) Spectroscopy at the $S$ K-edge
}

\author{
KATHLEEN E. VANDER KAADEN ${ }^{* 1}$ BRIAN KONECKE ${ }^{2}$
} FRANCIS M. MCCUBBIN ${ }^{2}$

${ }^{1}$ Jacobs JETS, NASA Johnson Space Center, 2101 NASA

Parkway, Houston, TX 77058, USA

${ }^{2}$ NASA Johnson Space Center, 2101 NASA Parkway, Houston, TX 77058, USA

(*correspondence: kathleen.e.vanderkaaden@nasa.gov)

The oxidation state(s) and speciation of S imparts a major geochemical control on the chemical affinity and behavior of $\mathrm{S}$ in magmatic systems. Under reducing conditions $(<\mathrm{IW}$ $+3)$, oxygen $\left(\mathrm{O}^{2-}\right)$ is replaced by sulfide $\left(\mathrm{S}^{2-}\right)$ on the anion sub-lattice of the silicate melt, and complexes with cations $[\mathrm{M}]$, where: $0.5 \mathrm{~S}_{2}+[\mathrm{M}] \mathrm{O}$ (silicate melt) $^{\text {(s) }}=0.5 \mathrm{O}_{2}+[\mathrm{M}] \mathrm{S}$ (silicate melt). The limiting solubility of sulfide in a silicate liquid is defined by the S content at sulfide saturation (SCSS), where:

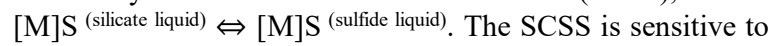
temperature, degree of melt polymerization (i.e., $\mathrm{SiO}_{2}$ content), oxygen fugacity $\left(\mathrm{fO}_{2}\right), \mathrm{FeO}$ content, and to a minor degree pressure. In highly reduced systems similar to those seen on Mercury and the aubrite meteorite parent bodies (APB) (IW-3 to IW-8), the SCSS is highly sensitive to $\mathrm{FeO}$ concentrations of the melt. SCSS estimates for mercurian lavas and APB remain enigmatic, in part due to their low-FeO $(<2 \mathrm{wt} \% \mathrm{FeO})$, high-S $(>1 \mathrm{wt} \% \mathrm{~S})$ and exceedingly low $f \mathrm{O}_{2}$ characteristics. Additionally, initial experimental results under highly reduced conditions show a preference for $\mathrm{Mg}$ to be incorporated into the sulfide phase over $\mathrm{Ca}$. However, there is a much stronger correlation between $\mathrm{Ca}$ and $\mathrm{S}$ on the surface of Mercury compared with Mg and S. Micro-XANES spectroscopy is a synchrotron based technique used to probe the electronic and chemical structure of materials and compounds and is a well-established method that enables in situ, high-resolution, and non-destructive analyses. Here we examine $\mathrm{S}$ speciation at low $\mathrm{O}_{2}$ using a sulfur-rich diopside melt composition and silicon-rich metal at $1 \mathrm{GPa}$ and $1600^{\circ} \mathrm{C}$. All sulfur was added to the experiments as $\mathrm{S}^{0}$ or $\mathrm{FeS}$ to examine the effect of $\mathrm{Fe}$ on $\mathrm{S}$ speciation. Results from this experimental study, compared with previous literature data, will help to elucidate the preference of $\mathrm{Ca}$ and $\mathrm{Mg}$ in sulfides and provide insights into the oxidation state, speciation, and bonding environment of $\mathrm{S}$ in the experimental charges. 